\title{
REPORTS OF MEETINGS
}

\author{
Seventh AMQUA - Character and Timing of Rapid Environmental and Climatic Changes - \\ 7th American Quaternary Association Conference, \\ 28-30 June, 1982, Seattle, U.S.A.
}

The focus of this conference was on rapid, perhaps catastrophic environmental changes. How can they be recognized in the geologic, paleontologic and paleoclimatic records? How precisely can we resolve rapid events? Can we use this information to predict rapid environmental changes that might affect human populations in the very near future? The first day was devoted to an examination of the sensitivity of natural systems - climatic, oceanographic, and terrestrial - to change, as well as an evaluation of the degree of resolution of available dating systems. On subsequent days specific environments were discussed: terrestrial, glacial, sea-levels, lacustrine, as well as man's interaction with these environments.

As would be anticipated, our resolving power varies considerably from system to system, and the conception of rapidity varies accordingly. As a result the program was rather uneven, with oceanographers and students of terrestrial environments unable to resolve their chronologies more finely than a few hundred to even a thousand years while those working on lake varves or Greenland ice cores can resolve their chronologies to the season or the year. The definition of 'rapid' was never really addressed during the conference, and it was clearly bothersome that sharp changes observable in one system cannot be detected, or are extremely blurred, in another.

Leading off the discussion of sensitivity, Roger Barry (Boulder) outlined the possible effects of various external and internal forcings on a transitive $v s$ an intransitive climatic system. On one hand, a given forcing function may produce stepwise changes in some parts of Earth, but gradual changes elsewhere. On the other hand, he addressed the complication of Earth having multiple equilibrium modes, e.g., glacial and non-glacial, such that gradual changes may take place within one of these modes in response to a certain forcing or, under certain unstable conditions, rapid shifts from one equilibrium state to the other may occur. However, the complex nature of Earth's climatic system renders our understanding of its response on time scales longer than $10-20$ years very hypothetical.

In seeking rapid responses in the oceanic system Claes Rooth (Miami) suggested that relatively sudden changes in thermohaline circulation could be induced by sea-level changes. The latter cover and uncover the continental shelves where shallow, warm waters are conducive to high rates of evaporation, hence augmenting or decreasing the salinity. An even more rapid change might be expected as a result of strong swings of the polar front in the North Atlantic, as documented by Ruddiman and McIntyre near the Pleistocene/Holocene transition. This area is critical 
because it is the site of production of most of the North Atlantic Deep Water, which in turn plays a role of heat source or sink. Rapid sinking of relatively warm, saline water in this region could result in transient storage of relatively warm water in the deep ocean during a glaciation. Rooth emphasized carefully the hypothetical character of such speculation based on theoretical models of ocean circulation.

After Minze Stuiver (Seattle) reviewed the uncertainties involved in ${ }^{14} \mathrm{C}$ production through time, Herbert Wright (Minneapolis) surveyed the sensitivity of natural systems to climatic change, setting the stage for subsequent sessions.

William Watts (Dublin) presented his ideas on biotic response to rapid environmental changes, by no means limited simply to climatic changes. The vegetational record, in particular, is difficult to evaluate in these terms in large part because both a sudden stepwise change and a gradual unidirectional change could lead to the same kind of pollen record. The growth of a population from a few pioneers to a stable size is a gradual process even if initiated suddenly, and time for migration must also be allowed. Other rapid changes, such as blanketing an area with thick volcanic ash or epidemic disease, can also trigger changes in vegetation. The response time to such a volcanic event has not yet been adequately evaluated. (Amazingly this was one of the very few references to volcanic activity as a cause of rapid environmental change, although the conference was held in the shadow of Mount St. Helens!) The chestnut blight, which eliminated this major forest taxon in the eastern United States in some three decades, may find parallels in the 'elm decline' in Europe and the 'hemlock decline' in North America, both of which occurred about 5,000 years ago, according to pollen records. In discussion Margaret Davis (Minneapolis) pointed out the difficulty of seeing very short term vegetation responses in the pollen record. Observed climatic and concomitant vegetational changes do not appear in pollen diagrams. Even the Little Ice Age is barely detectable and even then only at a small number of sites. Several speakers emphasized the necessity to look in marginal (ecotonal) areas for the most sensitive records of vegetation response.

In dealing with the impact of rapid changes on society Karl Butzer (Chicago) stated plainly at the outset that he feels that human responses are 'unpredictable'. Many variables are involved, of course, not the least of which is that man is a rational creature who can weigh choices among several possible responses. Moreover, group decisions may override individual choices. Furthermore, human perception of the impending environmental change may not be directly related to the actual amplitude of the change. American 'dust-bowls' and Sahelian droughts were cited as examples of varied responses in historic time, and declining Nile flood levels combined with political instability brought down the New Kingdom in Egypt in the 12th century B.C. Butzer closed his remarks with a challenge to Quaternary scientists to bring their understanding of the world climatic system to bear on the impending crisis stemming from the increased atmospheric $\mathrm{CO}_{2}$ flux from the burning of fossil fuels. Based on analogy with mid-Holocene Hypsithermal climates, he visualizes that failing crops in the 'breadbaskets' of North America and the Soviet Union could trigger political strife. In rebuttal, both Wayne Wendland (Urbana) and Donald Grayson argued that the Hypsithermal is perhaps not a good analog because several important boundary conditions for Hypsithermal climate do not exist now.

Glaciers were examined from two points of view, first in terms of the whole glacier's response to environmental change and secondly in terms of records preserved in the ice itself. Stephen Porter (Seattle) emphasized the difficulty in interpreting a glacier's response because of lag time involved in building a moraine, which is our record of the response, and because of differing res- 
ponses of neighboring glaciers as a function of their size and topographic situation relative to equilibrium-line altitudes. Chester Langway gave a sneak preview of some results from the DYE-3 ice core recently recovered in southern Greenland. The quality of core recovery was much better than that in the Camp Century core studied previously, allowing much closer inspection of yearto-year changes. Especially spectacular were chemical analyses that suggest 4 - to 6 -fold increases in chloride and sulfate concentrations within a 10-70 year interval about 10,400 years ago. Even though some modifications of these results may be expected when changing snow accumulation rates are taken into account such dramatic changes must reflect an abrupt environmental change independent of the ice sheet itself at the beginning of the Holocene.

One might feel intuitively that sea-level would change only sluggishly in response to an environmental change since it is primarily a function of the growth and decay of the large, sluggish ice sheets. In fact, as Thomas Cronin (Reston) summarized, there are still many uncertainties in our knowledge of the eustatic curve for the last 140,000 years, especially for the troughs, and rates of sea-level change are averaged over 100's to 1000's of years for lack of closer control points. Especially lacking are climatic data corresponding to sea levels, high or low. However, interbedded ostracodes and pollen now indicate lags between temperatures and sea levels. Cooling preceded marine regression at the beginning of the Wisconsinan glaciation (post-72,000 BP), and the climate remained cool into the early interglacial times when sea level had recovered. Cronin's data from the east coast of North America were confirmed by evidence from California (Lajoie) and the U.K. (Bowen). The fastest rates of sea-level rise now seem to be associated with the deep-sea terminations, amounting to about $3 \mathrm{~cm} / \mathrm{yr}$.

The final session was devoted to lacustrine systems, keynoted by Roger Anderson (Albuquerque) who described studies on varves, of Permian and of Quaternary age, as well as artificial varves produced in clever sediment traps. Here there is a wealth of detail and a high degree of chronological resolution, even daily and seasonal, as well as annual. There is in fact almost an embarassment of riches in these records, making it difficult to see the forest for the trees, and they tend to be statistically 'noisy'. Nevertheless Anderson believes that it will be possible to develop transfer functions and to sort out endogenous and exogenous processes in the lake basin. In discussion Kenneth Lajoie (Menlo Park) emphasized old shorelines as features of gross changes in lake regimes, and David Frey (Bloomington) suggested that some of the more useful information from lakes will be found in the near-littoral zones, not in the more stable environments of the deep, central basins, nor in the widely spaced raised shorelines.

The conference closed with remarks volunteered by J. Murray Mitchell (Washington) relative to the possible effects of the increasing atmospheric $\mathrm{CO}_{2}$ content. He suggested that Earth climate will probably pass through a transitional phase of some 200 years before settling into a new equilibrium, which may last some 1,000 years. He asked the question, 'When did past climates change as rapidly as we anticipate that they will during this transitional phase?', and suggested that it may be on the scale of the Pleistocene/Holocene (Younger Dryas) transition.

Abstracts of papers presented by the principal speakers, by some of the discussants, and of numerous poster papers on display at the conference are available from the AMQUA Treasurer, J. E. King, Illinois State Museum, Springfield, IL, 62706, U.S.A.

William R. Farrand

Department of Geological Sciences, University of Michigan, Ann Arbor, Michigan 48109, U.S.A. 